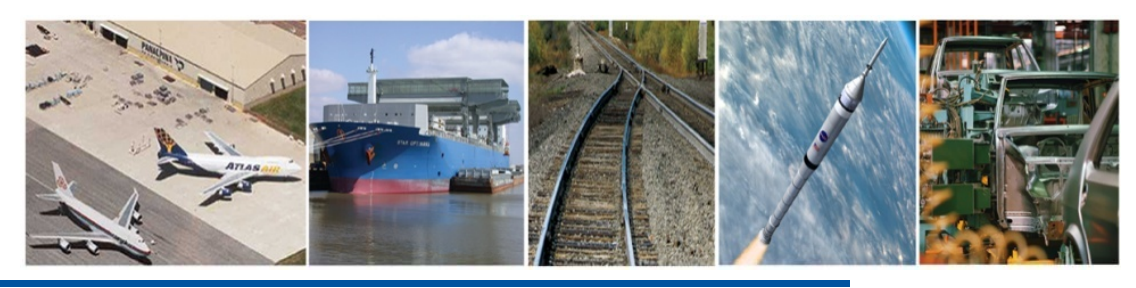

\title{
SCRL-Model for Human Space Flight Operations Enterprise Supply Chain
}

\section{IEEE Aerospace Conference \\ Big Sky, Montana}

March 6-13, 2010

Brian Tucker

University of Alabama in Huntsville

256.824.2957

brian.tucker@uah.edu 


\section{The Need}

- Standard approach to evaluate and configure adaptable and sustainable program and mission supply chains at an enterprise level

- End-to-end view

- Total Lifecycle

- Evaluate the readiness of the supply chain during the supply chain development phases 


\section{Enterprise Supply Chain Management}
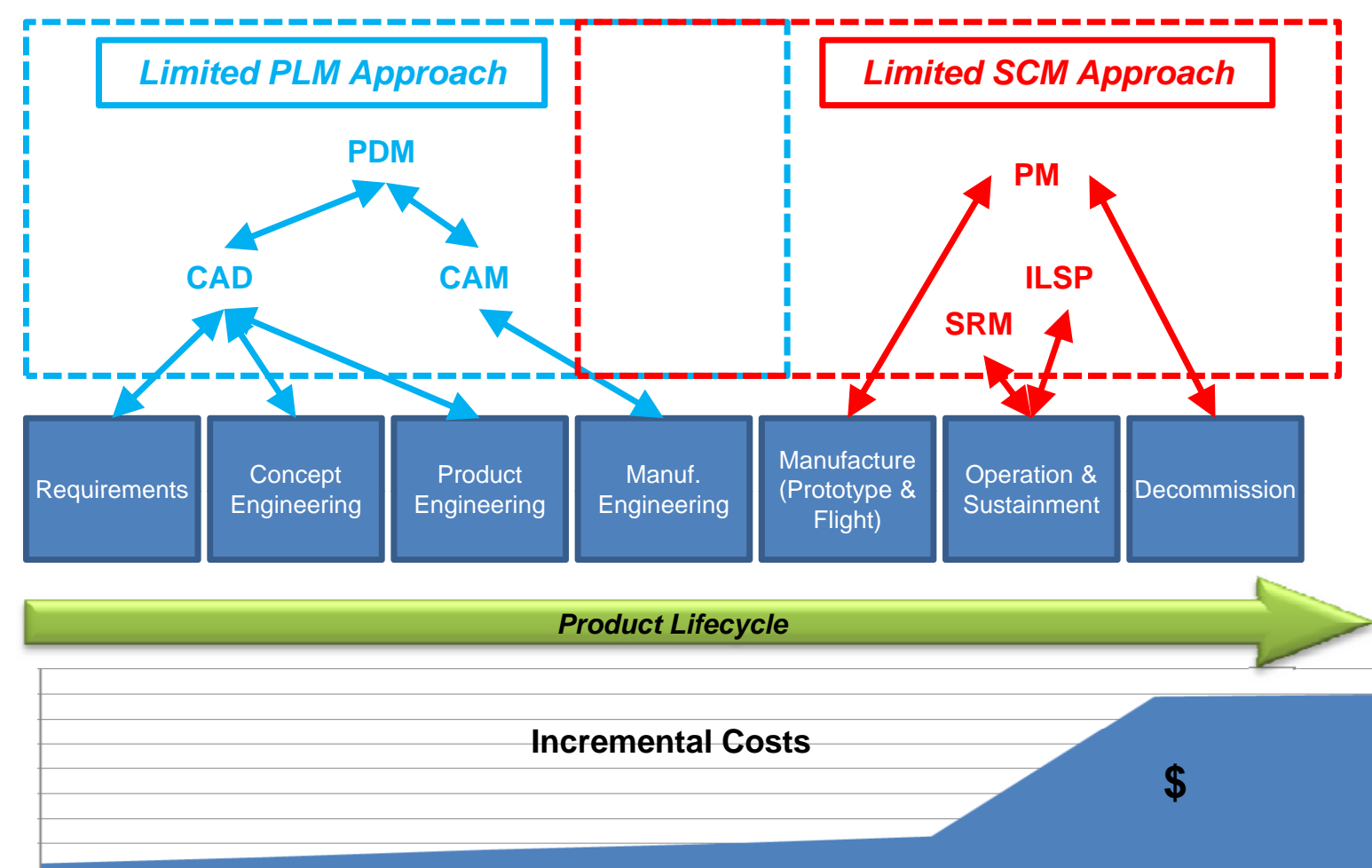

How do we measure SC readiness? How do we construct this type of SC?
- Total Visibility

- Total Lifecycle

- Meeting Mission Requirements

- On time \& at cost

- Sustainable

- Adaptable

- Optimized

- Mitigated Risks

- Continuous Improvement

- Viable Suppliers 


\section{SCRL Model Development}



$>$ Merge systems engineering project development process with enterprise supply chain development best practices and metrics (e.g. SCOR®)

$>$ Correlate to current MRL, MRA and TRL standards and expand to encompass total supply chain

$>$ Utilize a standardized assessment-based measurement model 




\section{SCRL Model}

SCRL 1

Immature High Risk High Cost

-Early phases of development

-Limited to next tier relationship

- Communication and information limited to single orders

- Modeling and

Simulation

technologies not used

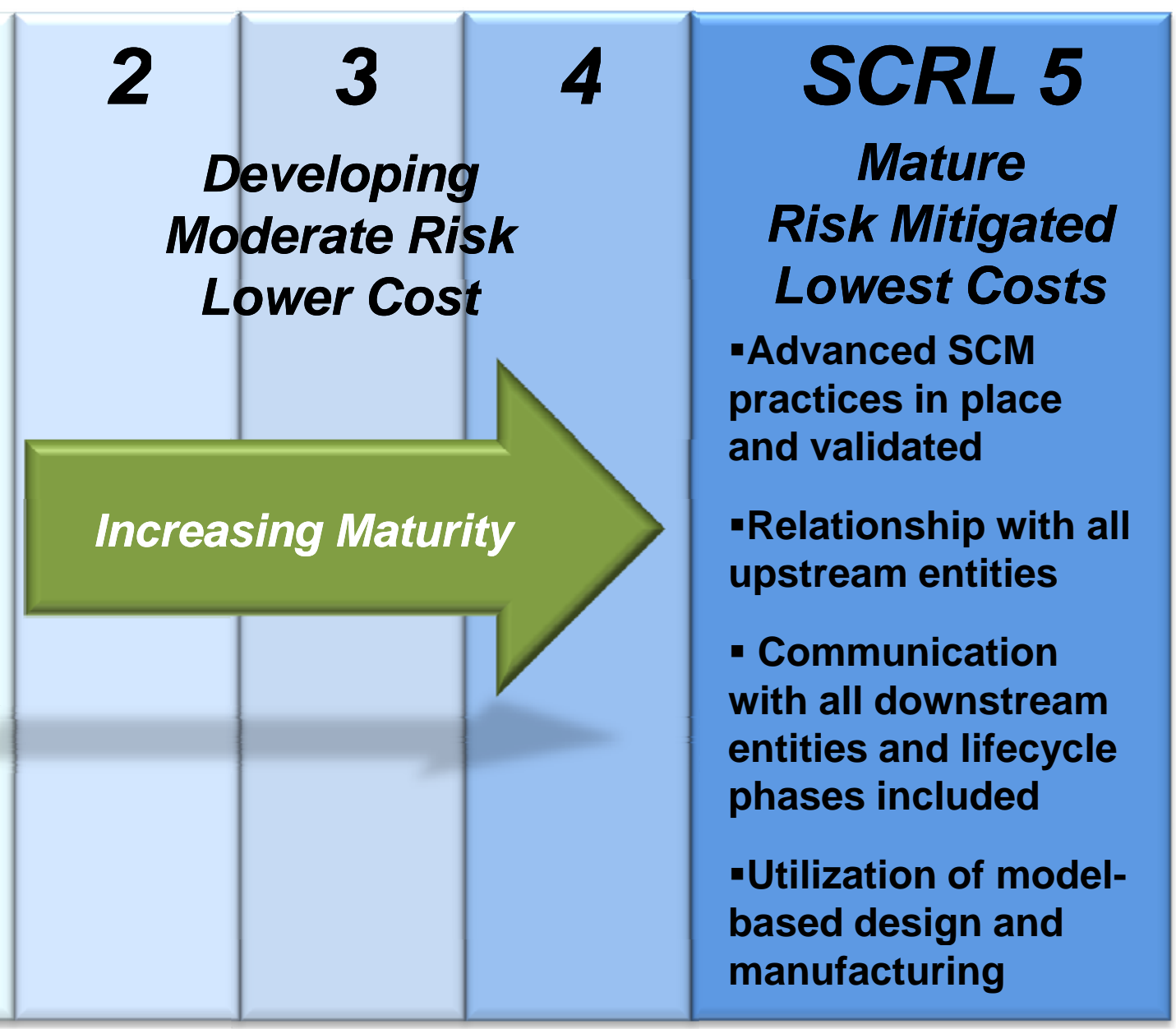


Defense Acquisition Framework and Relationship to TRL and MRL

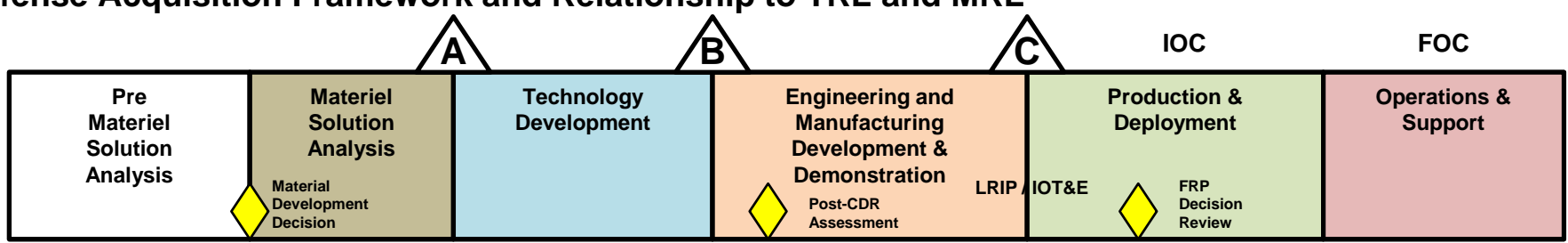

Review and Audits

Technology Readiness Levels

\begin{tabular}{|l|l|l|l|l|l|l|}
\hline TRL1 & TRL 2 & TRL 3 & TRL 4 \\
\hline
\end{tabular}



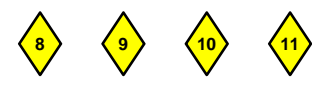

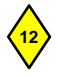

\begin{tabular}{|l|l|}
\hline TRL 8 & TRL 9 \\
\hline
\end{tabular}

\section{Manufacturing Readiness Levels}

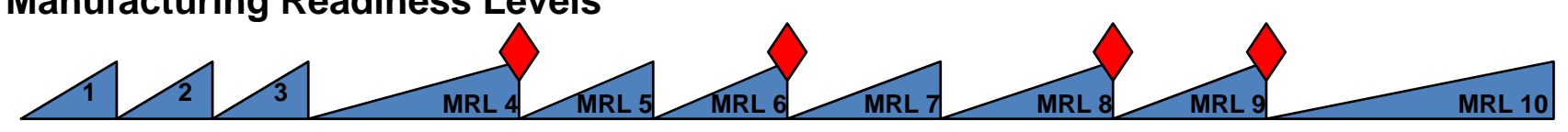

Source: Department of Defense, Manufacturing Readiness

Assessment (MRA) Deskbook, May, 2009

\section{SC developed along with Tech and Mfg}

Supply Chain Readiness Levels

SCRL 1
SCRL 2
Supply Chain developed in conjunction with technology and manufacturing

Established reviews and audits trigger evaluation of supply chain

Levels in technology and manufacturing readiness are considered from a SC perspective

SCRL 5 
UAHuntsville Office for Enterprise Innowation and Sustainability

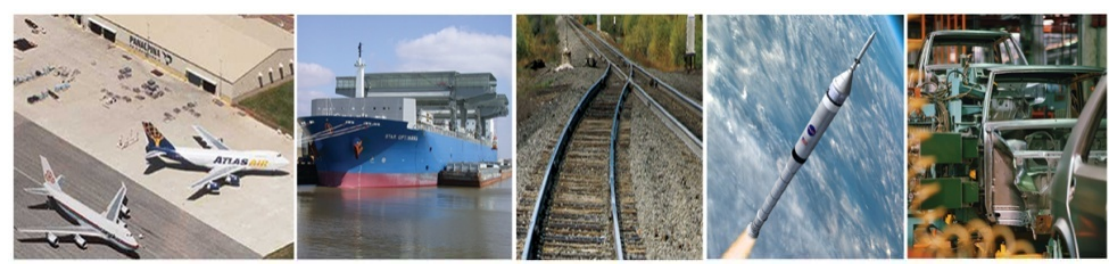

\section{SCRL: Supply Chain Characteristics}

\begin{tabular}{|c|c|}
\hline Inventory & Strategic raw material, WIP and FG placement in SC \\
\hline Strategic Sourcing & Sourcing decisions benefit enterprise, optimum number of SKUs \& supp. \\
\hline Visibility & Ability to see varying levels of the SC \\
\hline Suppler lOust Relationships & Working relationships at varying levels of the SC, Improvement focus \\
\hline Price Adaptability & Impact of variation in the price of commodities \\
\hline Collaboration & Flow of information up and down the supply chain \\
\hline Lifecycle Awareness & SC visibility and awareness of the current lifecycle phase \\
\hline Modeling \& Simulation & Apply modeling and simulation to improve SC \\
\hline Performance Measurement & Metrics used to measure and improve supply chain \\
\hline Fisk Management & Including obsolescence, sole-sourcing, counterfeit parts \\
\hline Criticality Focus & Focus level on critical parts, path and suppliers \\
\hline Sustainability & Long term viability of the industrial base \\
\hline Manufacturing Readiness & Monitoring manufacturing readiness of the SC \\
\hline Technology Readiness & Monitoring technology readiness of the SC \\
\hline Sub-Tier Management & All levels of SC adhere to SCRL standards \\
\hline
\end{tabular}




\section{UAHuntsville \\ THE UNIVERSITY OF ALABAMA IN HUNTSVILLE}

Office for Enterprise Innovation and Sustainability

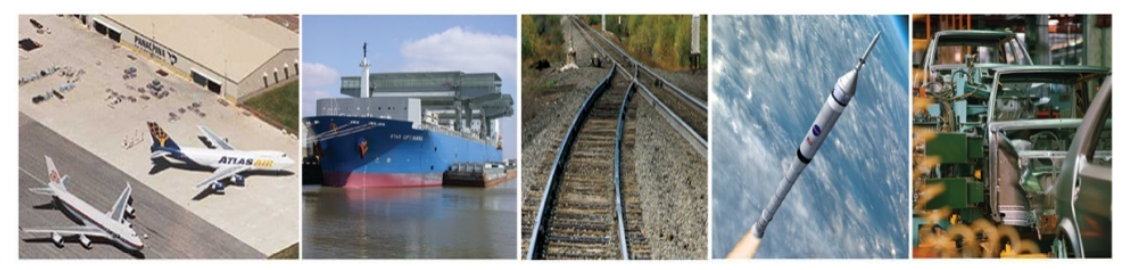

\section{SCRL: Supply Chain Characteristics}

\section{Inventory SCRL Requirement}

SCRL 1 Inventory levels not known throughout the SC.

Inventory is not optimized even at the local level.

SCRL 2 Inventory levels are being monitored at the local level. Stockouts and low inventory turns are common.

Inventory levels are defined and managed locally in order to

SCRL 3 satisfy next-level customer demand. Efforts are being made to identify major stockpiles of inventory throughout the supply chain.

Inventory is distributed throughout the supply chain with

SCRL 4 managed buffers at supply chain node interfaces. VMI may be in place at some locations.

Inventory is strategically placed throughout the supply chain to

SCRL 5 minimize total supply chain inventory costs while still satisfying the readiness demands of the system 


\section{SCRL: Supply Chain Characteristics}

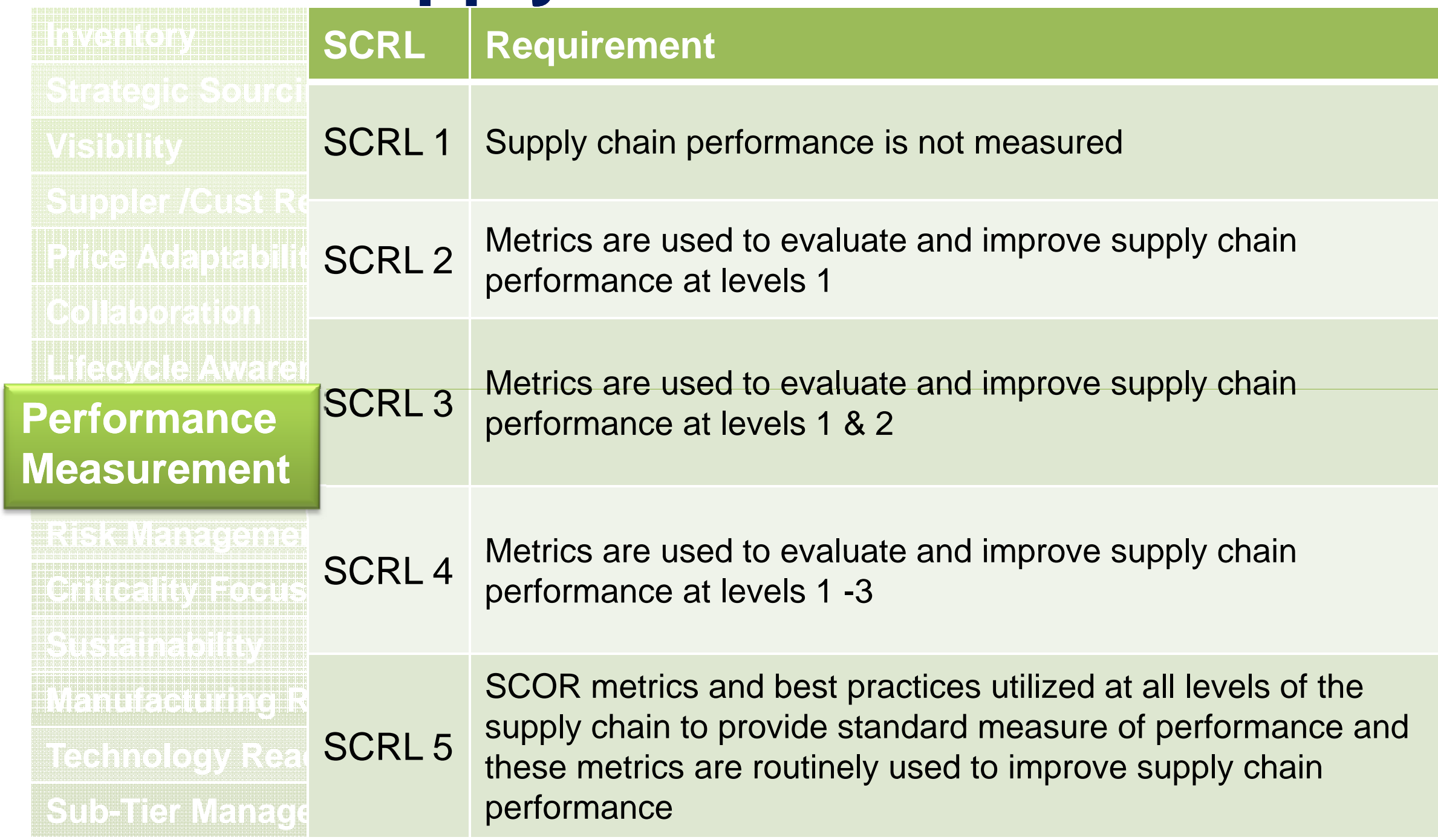




\section{SCRL: Level \& Assessment}

\section{Inventory}

Strategic Soureing

Visibility

Suppler ICust Relationships

Price Adaptability

Collaboration

Lifecycle Awareness

Modeling \& Simulation

Performance Measurement

Risk Management

Criticality Focus

Sustainability

Manufacturing Readiness

Technology Readiness

Sub-Tier Management

\section{SCRL Assessment}

An Assessment will be used to evaluate the SC readiness

Assessment questions and performance criteria established for each characteristic to define SCRL

$\square$ Overall SCRL for the supply chain being evaluated will be determined by the minimum SCRL.

$\square$ The assessment results could then be used to identify the specific supply chain characteristics and practices that should be addressed to increase the SCRL and reduce the risk and cost before moving to the next development phase. 
UAHuntsville Office for Enterprise Innowation and Sustainability



\section{SCRL: Levels by Characteristic}

\begin{tabular}{|c|c|c|c|c|c|}
\hline Inventory & SCRL 1 & SCRL 2 & SCRL 3 & $\operatorname{SCRL}_{4}$ & SCRL 5 \\
\hline Strategie Soureing & SePl-1 & Serite2 & Seding & $\operatorname{SeR} V_{4}$ & SePl 5 \\
\hline Visibility & SCRL 1 & SCRL 2 & SCRL 3 & $\operatorname{SCR} V_{4}$ & SCRL 5 \\
\hline Suppler Cust Relationships & sodilin 1 & SORL 2 & SCRLE & $\operatorname{Set}_{4}$ & Sormin 5 \\
\hline Price Adaptability & SCRL 1 & SCRL 2 & SCRI 3 & SCRL 4 & SCRL 5 \\
\hline Collaboration & Sog & SCPL2 & Som 3 & $\operatorname{sedvL}_{4}$ & sopres \\
\hline Lifecycle Awareness & SCRL 1 & SCRL 2 & SCRL 3 & $\operatorname{SCR} V_{4}$ & SCRL 5 \\
\hline Modeling \& Simulation & SOPII 1 & SOPL 2 & 50123 & $\operatorname{SCRL}_{4}$ & SOPI 5 \\
\hline Performance Measurement & SCRL 1 & SCRL 2 & $\operatorname{SCR} V_{3}$ & SCRL 4 & SCRL 5 \\
\hline Risk Management & Septin & SCRL 2 & SCRI/3 & SCRL 4 & SCPI 5 \\
\hline Criticality Focus & SCRL 1 & SCRL 2 & $\operatorname{SCR} V_{3}$ & SCRL 4 & SCRL 5 \\
\hline Sustainability & SORL 1 & SCRL 2 & SCRL 3 & $\operatorname{SCR} V_{4}$ & SORL 5 \\
\hline Manufacturing Readiness & SCRL 1 & SCRL 2 & SCRL 3 & $\operatorname{SCRL} 4$ & SCRL 5 \\
\hline Technology Readiness & Soril 1 & sedi 2 & Seras & $\operatorname{sen}_{4}$ & sepris \\
\hline Sub-Tier Management & \multicolumn{2}{|c|}{ Example } & SCRL 3 & $\operatorname{sCRL} 4$ & SCRL 5 \\
\hline
\end{tabular}




\section{SCRL \& the Extended Supply Chain}

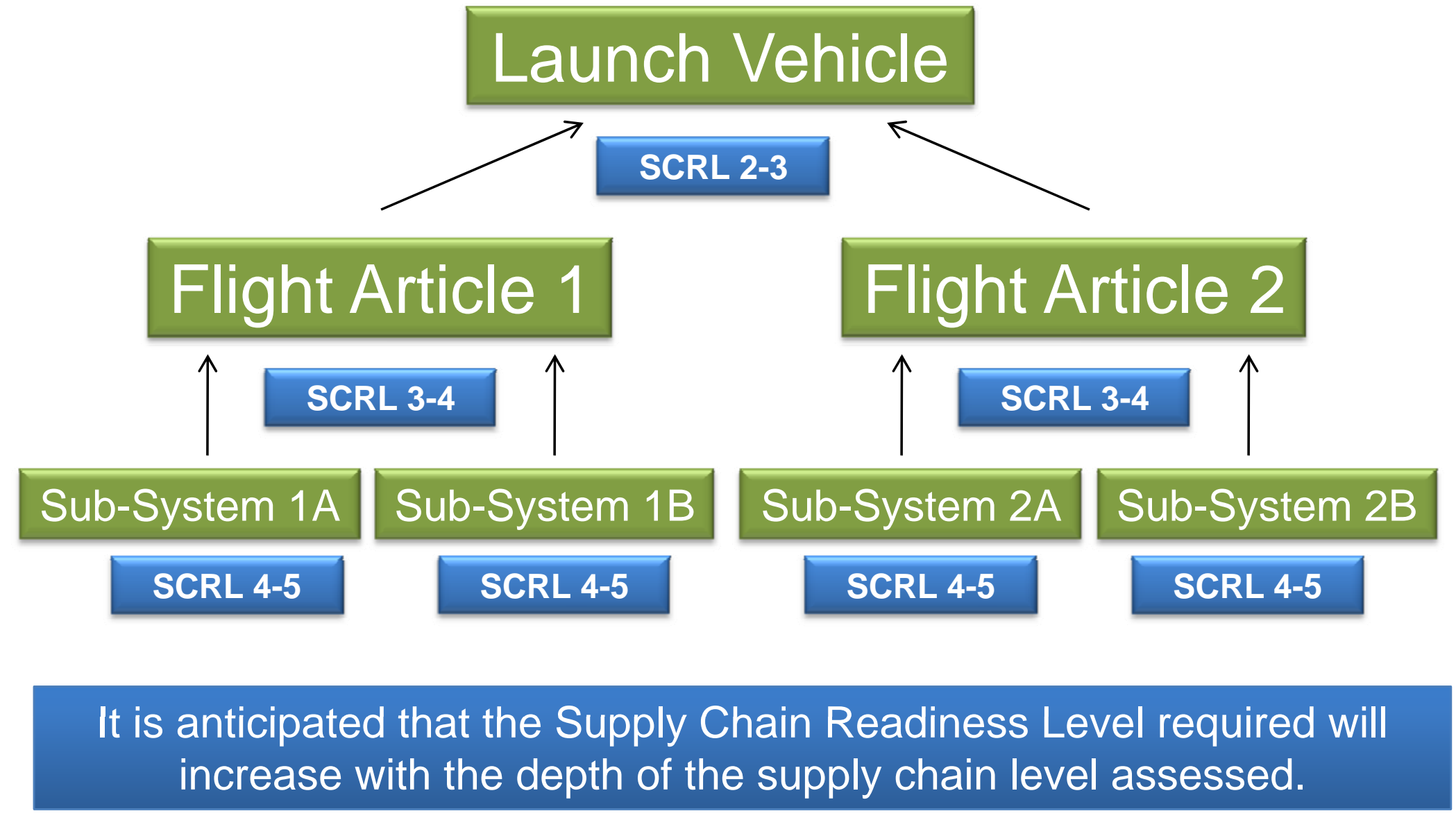




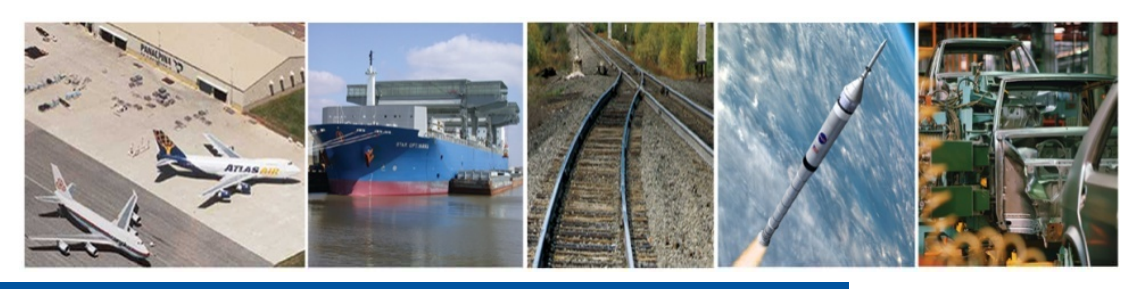

\section{Benefits of using SCRL}

- Standard Assessment and Construction Model

- Concurrently addressing SCM issues in the same manner

- Risk mitigation can begin in the earliest phases and accurate lifecycle costs can be assessed and controlled.

- Proactive Collaboration

- SC entities develop collaborative structures and relationships

- Improved visibility throughout SC

- Continuous Improvement

- Identify opportunities for improvement

- Monitor as SC entities and conditions change

- Framework for Contracts and Data Requirements 


\section{Path Forward}

- Complete development of matrix

- Refine levels and threads

- SCRLs are in early stage of development

- Develop body of knowledge/references to support development

- Peer review of SCRL SC characteristic matrix

- Acceptance by government agency

- Acceptance by industry

- Develop SCRL Assessment

- Perform pilot projects to validate

- Good, Bad, OK 